\title{
Effects of Climate Change on Occurrence of Aflatoxin and its Impacts on Maize in India
}

\author{
Meena Shekhar ${ }^{1 *}$, Nirupma Singh ${ }^{2}$, Sunaina Bisht ${ }^{2},{\text { Vimla } \text { Singh }^{1} \text { and Arvind Kumar }}^{1}$ \\ ${ }^{1}$ Indian Institute of Maize Research, Pusa Campus, New Delhi-12, India \\ ${ }^{2}$ Indian Agricultural Research Institute, Pusa Campus, New Delhi-12, India \\ *Corresponding author
}

\begin{abstract}
A B S T R A C T
Climate change is a key factor for emerging food and feed safety issues all over the world. Aflatoxins are potent mycotoxins that cause developmental and immune system suppression, cancer, and death. The expected impact on the occurrence of mycotoxins in food and feed is of great concern. Among mycotoxins, aflatoxins have acute and chronic toxicity that cause suppression of immune system and even cancer. Hence, its

Keywords

Aflatoxins, Aspergillus flavus, Climate change, Fungi

Article Info

Accepted: 02 May 2018 Available Online: 10 June 2018 concentration in agricultural food, feed and their commodities is regulated worldwide. Fungi Aspergillus is responsible for aflatoxin contamination in maize grains. Maize grain contaminated with aflatoxin is responsible for significant economic loss for producers, marketers, and stakeholders. The possible change in patterns of aflatoxin occurrence in crops due to climate change is a matter of concern that may require anticipatory actions. Aflatoxin contamination influenced by climate, by direct influencing population of $A$. flavus on maize that includes changes in the quantity of aflatoxin-producers in the environment and alterations to fungal community structure. Fluctuations in climate also influence predisposition of hosts to contamination by altering crop development and by affecting insects that create wounds on which aflatoxin-producers proliferate. Aflatoxin contamination is prevalent both in warm humid climates and in irrigated hot climatic condition. Generally, if the temperature increases in cool or temperate regions, the respective areas may become more susceptible to fungi Aspergillus as a result aflatoxins contamination increases. However, tropical countries may become unfavourable for growth of aflatoxin producing fungi. The objective of this paper is to review the potential impact of climate change on aflatoxin that contaminate maize in India, and to highlight key research questions and approaches for understanding this impact.
\end{abstract}

\section{Introduction}

Maize is one of the most important agricultural commodities worldwide after wheat and rice in terms of production, consumption, and trade. Hence, naturally occurring aflatoxin contamination in maize has important ramifications for both global trade and health. Aflatoxins, are cancerous secondary metabolites produced primarily by the fungi Aspergillus flavus and Aspergillus parasiticus, which contaminates various staple foods, including maize, groundnuts and tree nuts. Aflatoxin is most prevalent in important crops in tropical and subtropical regions of the world, and may occur in the 
field and post-harvest under suboptimal storage conditions. It has been estimated that 5 billion people worldwide are exposed to uncontrolled aflatoxin in the diet (Strosnider et al., 2006). Acute aflatoxin causes hepatitis, impaired growth in children, jaundice and gastrointestinal injuries with high morbidity and mortality (CDC, 2004). Prolonged chronic exposure is suspected to increase the risk for hepatocellular carcinoma (Marcel and Wild, 1995; Julia, 2005). In many parts of the world, particularly in Asia and sub-Saharan Africa, individuals are exposed both to high levels of aflatoxin and chronic hepatitis B virus (HBV) infection, which has been shown to greatly increase liver cancer risk (Qian et al., 1994): a multiplicatively greater risk of developing HCC than those exposed to aflatoxin or HBV alone (Liu et al., 2012). Mainly, A. flavus comes in contact with crops before harvest, it however remains associated with the crop through harvest and storage (Lillehoj, 1987).

In India, human disease outbreaks attributable to consumption of aflatoxin-contaminated maize have been reported from district of Banswara in Rajasthan and Panchmahal in Gujarat (Krishnamachari et al., 1975). The occurrence of aflatoxins and ochratoxin A has been reported in poultry feeds from India (Gong et al., 2003; Thirmula Devi et al., 2002). These observations reinforce the need for aflatoxin exposure intervention strategies within countries. Aflatoxin contributes to significant economic losses in maize which prevents these commodities from meeting international standards governing agricultural trade and food safety. Toxin production and fungal populations in maize have been found to depend on several interacting factors that stress corn plants (Payne, 1992). Stress factors include low moisture content of soil, high daytime maximum temperatures, high night time minimum temperatures, and nutrient-deficient soils (Miller et al., 1983;
Widstrom et al., 1990; Abbas et al., 2002). India being a large country, there is extreme diversity in soils and climatic condition and maize is grown in a wide range of environments, extending from extreme semiarid to sub-humid and humid regions (Shekhar et al., 2016). The European Commission has proposed maximum allowable limits for aflatoxin in certain foods. The permissible limit of aflatoxin in foods for human consumption is 4-30 ppb, depending on the country involved (FDA 2004; Henry et al., 1999). In the United States, $20 \mathrm{ppb}$ is the maximum aflatoxin residue limit allowed in food for human consumption (FAO 2003). Due to aflatoxin contamination the food products cannot be exported leading to financial losses. In developing countries drought stress may be particularly important in terms of food security. Maize is particularly prone to infection during water stress. This leads to increased preharvest aflatoxin contamination affecting nutritional quality to significantly impact on consumption or the ability to export.

\section{Impact of climate change on aflatoxin contamination}

The effect of climate change on mycotoxins is extremely complex, which involves many factors. There is an increase in average global air temperatures and changes of precipitation distribution when we talk about the effect of climate change however, an increase in the variability of the weather with more extreme events such as heat waves, droughts and extreme precipitation (Field, 2012; IPCC, 2007; Pachauri and Reisinger, 2007). The global, climate change is expected to negatively affect agricultural production (Pachauri and Reisinger, 2007). In addition that, climate change also affects the prevalence of fungal species that can infect the crop, associated plant diseases and mycotoxin contamination (Gregory et al., 
2009; Madgwick et al., 2011). The population of aflatoxin producing fungi associated with crops and soils varies with climate. These fungi compete poorly under cool conditions and the population of A. flavus in cool areas (temperature minima $>20^{\circ} \mathrm{C}$ ) is low compared to warmer regions (temperature minima $<25^{\circ} \mathrm{C}$ ) where Aspergillus sp are common throughout soils, air, and on crop surfaces (Manabe et al., 1978; Shearer et al., 1992). Maize crop grown in warm climates and prone to infection by A. flavus however, in some regions, infection occurs when temperatures rise is coupled with drought (Sanders et al., 1984; Schmitt and Harburgh, 1989). These fungi are native to warm arid, semi-arid, and tropical regions with changes in climate resulting in large fluctuations in the concentration of aflatoxin production (Bock et al., 2004; Shearer et al., 1992). Climate also influences the types of aflatoxin producing fungi as a result aflatoxin-producing fungi differing geographically (Cotty, 1997; Horn and Dorner, 1998, 1999; Lisker et al., 1993). High temperatures and dry conditions favour growth and dispersal of spores of A. flavus that also impair growth and development of maize (Cotty and Jaime-Garcia, 2007). Drought together with high temperatures favours aflatoxin production in field (Payne, 1998).

However, insect damage plays an important role in predisposing to aflatoxin contamination, which will be affected by climate change in turn. Changes in climate result in large alterations in the quantity of aflatoxin producing fungi (Bock et al., 2004; Shearer et al., 1992). The population of Aspergillus associated with crops and soils varies with climatic conditions and compete with other fungi poorly under cool conditions as a result the population of A. flavus in such areas (Minimum $20^{\circ} \mathrm{C}$ ) is low compared to warmer regions (Minimum $25^{\circ} \mathrm{C}$ ). However aflatoxin producing fungi are common throughout air, soils, and crops (Shearer et al., 1992). Hence, a change in temperature towards the higher temperatures will tend to increase aflatoxin concentrations. Crops grown in warm climates have greater chance of infection by $A$. flavusand in some regions infection only occurs when temperatures rise in association with drought (Sanders et al., 1984; Schmitt and Hurburgh, 1989). Therefore Climate-change factors will have a profound effect on both growth and relative aflatoxin production. Paterson and Lima (2010) suggested that a major risk in developed countries will be in temperate climates when temperatures tend to increase $>30 \mathrm{C}$, which would be conducive to aflatoxin production and represent a significant risk. The fungal infection to build up aflatoxin can be caused during two distinct phases, during growth stage when crop is in the field and secondly during storage condition. However, only one stage is required for contamination.

\section{Pre-harvest contamination}

Field infection occurs during the development of the crop when A. flavus associated with cob in the field at the time of maturity of crop and infection often follows drought stress, insect injuries such fungal growth called pre-harvest contamination (Russel et al., 1976; Cotty 1991; Cotty, 2001). The second phase occurs after maturation when plant is exposed to warm moist conditions in the environment or during storage. Pre-harvest aflatoxin contamination of crops occurs in the temperate and tropical regions. Though, developing crops is supposed to be resistant to infection by $A$. flavus and subsequent aflatoxin contamination, unless environmental conditions favour fungal growth and crop susceptibility. Stressed plants under drought, insect damage are the most susceptible to fungal invasion and aflatoxin production. High temperature and drought, which often occur together during the growing season and 
likely contribute to poor kernel development, have been reported to increase growth of the fungus and toxin production (Payne, 1998).

A tan sooty black, greenish or greenish yellow mould grows on and between kernels. The damage is most common at or near the tip of the ear; silk infection is favoured by high night and day temperature. Sometimes the susceptible maize genotypes got infected with Aspergillus sp. at the time of silking. The infection goes through silk to the developing seed/grains but remained latent and cause decay at the time of maturity in the form of cob rot/ear rot, sometimes the grain remain infected but does not show any symptoms even at the time of maturity. Maize planted and harvested late and grown under nitrogen stress are more commonly contaminated with aflatoxins prior to harvest than maize grown under good management practices and supplied with adequate nitrogen. Such contaminated seed/grain again spoiled at the time of poor storage conditions due to colonization of Aspergillus sp. and other micro-flora and consequently aflatoxin contamination takes place that cause serious health hazardous problems in a wide range of animals, when used as feed.

\section{Post-harvest contamination}

Post-harvest contamination occurs worldwide when conditions in the storage favours for the growth of Aflatoxigenic fungi. Aflatoxigenic fungi can grow in feedlot manure (Hendrickson and Grant, 1971). It occurs if the produce is not handled properly to minimize the thriving of the fungal are most severe when crops are caught by rain just prior to or during harvest. During high humidity, initially dry seed develops water content conducive to contamination. The combination of moisture content and temperature favours fungal/molds infection as a result aflatoxin contamination increased.
The molds that start the deterioration process in stored grains can grow at low water active and these molds are known as xerophilic molds. These molds cannot be detected on freshly harvested grains as they occur in very low numbers. The most likely, the sources of contamination for xerophilic fungi are the silos or sheds themselves, but transport vehicles, dust etc. may also contribute to the contamination. As molds grow and become established their metabolic activities create microenvironments with elevated temperature and moisture content.

Aspergillus flavus in particular, only grows when relative humidity in the air is above 85 percent or moisture content in the grain is above 16 per cent. As the moisture content increases, conditions become suitable for other, less xerophilic molds in a process known as fungal succession (Wicklow 1995), Aspergillus sp. is common molds in some tropical countries like India which can grow in low water active value and cause loss of germination, deleterious qualitative change in maize grains in addition to the aflatoxin contamination which varies with climate both temporally and spatially. Thus seed kernels become contaminated with aflatoxin B1, both before and after harvest (Diener et al., 1987). The high health risk caused by aflatoxins leads to strict concentration limits in different countries.

\section{Importance of aflatoxin contamination in maize}

Aflatoxin contamination endangers the food supplies and health of both people and livestock. This threatens the economic livelihood of farmers, commercial feed users, and numerous feed and food industries. Unless aflatoxin levels in crops and livestock are effectively managed, national development efforts to achieve food security and improve health in Kenya will be 
undermined. The understanding of the outbreak and spread of aflatoxin in these areas is crucial to ensure food security and human safety. The knowledge of the impact of climate will allow development of improved management procedures, better allocation of monitoring efforts, and adjustment of agronomic practices in response to projected global climate change.

In developing countries like India, drought stress is particularly important in terms of food security. For example, marginal land where stress tolerant sorghum was previously grown is being replaced with maize in Maharashtra, Karnataka, Madhya Pradesh, Andhra Pradesh etc. Maize is prone to infection when water stress periods occur. This leads to increased aflatoxin contamination of such crops pre-harvest and post-harvest and can significantly impact on the ability to export the crop and also on the nutritional quality when consumed in rural subsistence communities.

\section{Prevention strategies}

Prevention of aflatoxin contamination for the purpose of public health importance and economic improvement is very important. Hence, a number of strategies for reduction and control of aflatoxin have been considered in different areas of world. The management of aflatoxing can be done by adopting following strategies:

\section{Pre-harvest strategies}

Use recommended plant population and crop production practices.

Use a balanced fertility programme

Timely irrigation to reduce drought stress Adopt GAP to minimize the insect damage
Timely harvest

Crop rotation is one technique that can prevent mycotoxin contamination.

\section{Post-harvest strategies}

Proper monitoring of temperature and relative humidity

Dry grains to obtain moisture contents below $14 \%$ immediately after harvest

Maintain hygiene and sanitation from harvest to storage

Segregate foreign materials and broken grains

Storage should be sealed, airtight container or structure to limit the presence of aerobic organisms

Clean, fumigate, or segregate maize grain as and when insects and molds are noticed

In conclusion, climate change will add new challenges related to the dynamics of pathosystems and future food security. There is a need for continuous monitoring of the climatic changes and its interaction with aflatoxin producing fungi and host. If the current climatic patterns continue in this century, aflatoxin concentrations in maize will likely to be increased, whereas some other toxins viz., DON levels may decrease.

However, climate change-induced alterations in cropping patterns or shifts in pathogen populations could create new opportunities for DON risk in areas where maize currently is not grown or is a minor crop, and where new, more aggressive isolates of $F$. graminearum occur. Overall it will increase the economic and health risks with consumption of aflatoxin infected maize. 


\section{References}

Abbas, H.K., Williams, W.P., Windham, G.L., Pringle, H.C., Xie, W. and Shier, W.T., 2002. Aflatoxin and fumonisin contamination of commercial corn (Zea mays) hybrids in Mississippi. J. Agric. Food Chem. 50, 5246-5254.

Bock, C.H., Mackey, B. and Cotty, P.J., 2004. Population dynamics of Aspergillus flavus in the air of an intensively cultivated region of south-west Arizona. Plant Pathol53, 422-433.

CDC (Centers for Disease Control and Prevention) (2004). Outbreak of aflatoxin poisoning-eastern and central provinces, Kenya, January-July, 2004. MMWR Morb. Mortal Wkly. Rep., 53: 790-792.

Cotty, P.J., 1991. Effect of harvest date on aflatoxin contamination of cottonseed. Plant Dis. 75, 312-314.

Cotty, P.J., 1997. Aflatoxin-producing potential of communities of Aspergillus section Flavi from cotton producing areas in the United States. Mycol. Res.101, 698-704.

Cotty, P.J., 2001. Cottonseed losses and mycotoxins. In: Kirkpatrick, T.L., Rothrock, C.S. (Eds.), Compendium of Cotton Diseases. The American Phytopathological Society, Minnesota, pp. 9-13.

Diener, U. L., Cole, R. J., Sanders, T. H., Payne, G. A., Lee, L. S., andKlich, M. L. (1987). Epidemiology of aflatoxin formation by Aspergillus flavus. Annu. Rev. Phytopathol., 25, 249-270.

FAO/WHO (Food and Agriculture Organization/ World Health Organization). 2003. "Assuring Food Safety and Quality: Guidelines for Strengthening National Food Control Systems." Rome: Food and Agriculture Organization and Geneva: World Health Organization.
Field, C.B., 2012. Managing the risks of extreme events and disasters to advance climate change adaptation: special report of the intergovernmental panel on climate change. Cambridge University Press, Cambridge, UK.

Food and Drug Administration (FDA), 2004. Compliance guidance manual. http://www.cfsan.fda.gov.

Gong, Y.Y., Egal, S., Hounsa, A., Turner, P.C., Hall, A.J., Cardwell, K.F. and Wild, P.C., 2003. Determinants of aflatoxin exposure in young children from Benin and Togo, West Africa: the critical role of weaning. Int. J.Epidemiol.32, 556-562.

Gregory, P.J., Johnson, S.N., Newton, A.C. and Ingram, J.S., 2009. Integrating pests and pathogens into the climate change/food security debate. J. Exp. Bot. 60, 2827-2838.

Hendrickson, D. A., and Grant, D. W. (1971). Aflatoxin formation in sterilized feedlot manure and fate during simulated water treatment procedures. Bull Environ Contam Toxicol., 6, 525-531.

Henry, S., Bosch, F.X., Troxell, T.C., Bolger, P.M., 1999. Reducing liver cancer global control of aflatoxin. Science 286, 2453-2454.

Horn, B.W., Dorner, J.W., 1998. Soil populations of Aspergillus species from section Flavi along a transect through peanut-growing regions of the United States. Mycologia 90, 767-776.

Horn, B.W., Dorner, J.W., 1999. Regional differences in production of aflatoxin B1 and cyclopiazonic acid by soil isolates of Aspergillus flavus along a transect within the United States. Appl. Environ. Microbiol65, 1444-1449.

IPCC (Intergovernmental Panel on Climate Change) (2007). "Climate Change 2007", the Fourth IPCC Assessment Report. 
(http://www1.ipcc.ch/ipccreports/index. $\mathrm{htm})$

Jaime-Garcia, R. and Cotty, P. J., 2007. Influences of application timing on sporulation of the biocontrol product Aspergillus flavus AF36 in cotton fields of Arizona.Phytopathology97, S168S168

Krishnamachari, K.A.V.R., Bhatt, R.V., Nagarajan, V. and Tilak, T.B.G., 1975. Hepatitis due to Aflatoxicosis-an outbreak in Western India. Lancet, 1(7915), 1061-1062.

Lillehoj, E.B., 1987. The aflatoxin in maize problem: The historical perspective. in: M. S. Zuber, E. B. Lillehoj and B. L. Renfro, (eds). Aflatoxin in maize: Proc. Workshop. International maize and wheat improvement centre, Mexico, DF, pp. 13-32

Liu, Y. and Wu F. Global burden of aflatoxininduced hepatocellular carcinoma: a risk assessment. Environ Health Perspect. 2010; 118(6): 818-24.

Madgwick, J.W., West, J.S., White, R.P., Semenov, M.A., Townsend, J.A., Turner, J.A. and Fitt, B.D., 2011. Impacts of climate change on wheat anthesis and Fusarium ear blight in the UK. Eur J Plant Pathol., 130, 117-131.

Manabe, M., Tsuruta, O., Goto, T. and Matsuura, S., 1978. Study on distribution of mycotoxin-producing fungy: (Part 4) Mycotoxin-producing ability of Aspergillus strains inhabited in Southeast Asia. Report of National Food Research Institute 33, 49-56.

Miller, J.D., Young, J.C. and Trenholm, H.L., 1983. Fusarium toxins in field corn. I. Time course of fungal growth and production of deoxynialenol and other mycotoxins. Can. J. Bot. 61, 3080-3087.

Pachauri, R.K. and Reisinger, A., 2007. Climate change 2007 synthesis report: summary for policymakers. IPCC Secretariat, Cambridge, UK.
Paterson, R. and Lima N., 2010. How will climate change affect mycotoxins in food? Food Res. Int. 43, 1902-1914 10.1016/j.foodres.2009.07.010

Payne, G.A., 1992. Aflatoxins in maize. Critical Reviews in Plant Sciences 10: 423-440.

Payne, G.A., 1998. Process of contamination by aflatoxin-producing fungi and their impact on crops. In: Sinha KK, Bhatnagar D, eds. Mycotoxins in Agriculture and Food Safety. Marcel Dekker, New York. pp. 279-306.

Qian, G.S., Ross, R. K., Yu,M. C., YuanJ.M., Gao, Y.T., Henderson, B.E., Wogan, G.N. and Groopman, J.D., 1994. A follow-up study of urinary markers of aflatoxin exposure and liver cancer risk in Shanghai, People's Republic of China Cancer Epidemiology, Biomarker and prevention. Vol. 3, Issue 1.

Russell, T.E., Watson, T.F. and Ryan, G.F., 1976. Field accumulation of aflatoxin in cottonseed as influenced by irrigation termination dates and pink bollworm infestation. Appl. Environ. Microbiol 31, 711-713.

Sanders, T.H., Blankenship, P.D., Cole, R.J. and Hill, R.A., 1984. Effect of soil temperature and drought on peanut pod and stem temperatures relative to Aspergillus flavus invasion and aflatoxin contamination. Mycopathologia, 86, 51-54.

Schmitt, S.G. and Harburgh Jr., C.R., 1989. Distribution and measurement of aflatoxin in 1983 Iowa corn. Cereal Chem. 66, 165-168.

Shearer, J.F., Sweets, L.E., Baker, N.K. and Tiffany, L.H. 1992. A study of Aspergillus flavus/A. parasiticus in Iowa crop fields: 1988-1990. Plant Dis. 76: 19-22.

Shearer, J.F., Sweets, L.E., Baker, N.K., Tiffany, L.H., 1992. A Study of Aspergillus flavus, Aspergillus 
parasiticus in Iowa Crop Fields-19881990. Plant Dis. 76, 19-22.

Shekhar M, Singh N, Kumar S, Kiran R. (2016) Role of mould occurrence in aflatoxin build- up and variability of Aspergillus flavus isolates from maize grains across India. Qual. Assur. Saf. Crop.2017; 9 (2): 171 \pm 178

Strosnider H, Azziz-Baumgartner E, Banziger M, Bhat RV, Breiman R, et al., (2006). Public Health Strategies for Reducing Aflatoxin Exposure in Developing Countries: A Workgroup Report. Environmental Health Perspectives, 12:1898-1903.

Thirmula, D.K., Mayo, M.A., Reddy, G. and Reddy, D.V.R., 2002. Occurrence of aflatoxins and ochratoxin $\mathrm{A}$ in Indian poultry feeds. J Food Prot. 65, 13381340.

Wicklow, D. T. 1995. The mycology of stored grain: an ecological perspective. In: Jayas, D.S., White, N.D.G. and Muir, W.E., ed., Stored grain ecosystems. New York, Marcel Dekker, pp. 197249.

Widstrom, N.W., McMillian, W.W., Beaver, R.W. and Wilson, D.M., 1990. Weather-associated changes in aflatoxin contamination of pre-harvest maize. Journal of Production Agriculture 3, 196-199.

\section{How to cite this article:}

Meena Shekhar, Nirupma Singh, Sunaina Bisht, Vimla Singh and Arvind Kumar. 2018. Effects of Climate Change on Occurrence of Aflatoxin and Its Impacts on Maize in India. Int.J.Curr.Microbiol.App.Sci. 7(06): 109-116. doi: https://doi.org/10.20546/ijcmas.2018.706.015 